\title{
INTERAKTIVITAS NARASI DALAM INFOGRAFIS DIGITAL PADA INFOGRAFIS TEMPO.CO
}

\author{
Ari Kurniawan, Agung Eko Budiwaspada, Irfansyah \\ (Email: ree_kurniawan@yahoo.com) \\ Program Studi Magister Desain \\ Fakultas Seni Rupa dan Desain \\ Institut Teknologi Bandung \\ Jl. Ganesha No. 10, Bandung,Indonesia.
}

\section{ABSTRAK}

Media jurnalistik online menggunakan infografis digital sebagai bentuk baru untuk menarasikan cerita. Penggunaan teks dan gambar yang interaktif menjadi cara baru dalam menarasikan suatu cerita di ruang digital. Dunia digital memiliki keterhubungan dan kedalaman informasi yang bisa ditata berlapis-lapis. Memahami media digital sebagai sebuah ruang yang memiliki lapisan kedalaman merupakan hal yang penting karena hal inilah yang membedakannya dengan media tradisional. Dalam penelitian ini akan dibahas satu infografis digital dari Tempo.co yang menuturkan mengenai kasus korupsi hakim Mahkamah Konstitusi Akil Mochtar. Infografis digital ini dianalisis dengan menggunakan prinsip desain interaksi dari Donald Norman dan model narasi interaktif dari Heer \& Segel. Dari hasil analisis disimpulkan bahwa desain elemen interaktif dari infografis digital ini memiliki tingkat keterlihatan yang rendah \& ketidakkonsistenan kode warna dalam umpan balik elemen interaktifnya, sehingga mengurangi kualitas afordansi dari elemen interaktif tersebut. Interaktifitas yang dibangun dalam infografis digital ini belum dirancang dengan baik berdasar pemahaman ruang digital \& prinsip utama desain interaksi. Infografis digital ini juga tidak mampu memaksimalkan potensi yang dimiliki ruang digital untuk mengalirkan narasinya dengan baik. Potensi ruang digital dan Interaktifitas yang bisa dirancang di dalamnya harus mempertimbangkan dengan baik pesan yang hendak disampaikan. Elemen interaktif dalam infografis digital harus menjadi bagian dari pesan, tdk hanya dekorasi tambahan. Antara fungsi visual, verbal dan interaktifitas dalam infografis digital harus bekerja secara berdampingan untuk memperjelas makna serta narasi informasi.
\end{abstract}

Kata Kunci: infografis; interaktivitas; narasi; media; online

\begin{abstract}
Online journalism media is now using digital infographic as a new form to narrate the story. They use interactive text and image as a new way to tell a story in the digital space. The digital world has connectivity and depth of information that can be arranged in layers. Understanding digital media as a space that has layers of depth is important because it is distinguish them from the traditional media. This study will discuss one of Tempo.co digital infographics that tells about the corruption of the Constitutional Court's judge, Akil Mochtar. This digital infographic was analyzed based on the interaction design principles of Donald Norman and interactive narrative models of Heer \& Segel. From the analysis, it can be concluded that Interactive element design in this digital infographic has a low level of visibility and inconsistencies in the color-coded feedback, thus reducing the affordance quality of the interactive elements. The interactive element in this digital infographic, wasn't properly designed based on the understanding of the digital space and the main principles of interaction design. This digital infographics is also not able to maximize the potential of the digital space to make the information flow accompanied by a good narrative. An interactive potential of the digital space should be designed by considering the message that has to be delivered. Interactive elements in digital infographic should be part of the message, not just a mere decoration. Visual, verbal function and interactivity in digital infographic should immerse together, in order to clarify the meaning and narrative of the information.
\end{abstract}

Keywords: infographic; interactivity; naration; online 


\section{PENDAHULUAN}

Internet telah mengubah cara media jurnalistik dalam menyampaikan informasi. Internet juga mengubah cara pembaca mengalami informasi tersebut. Internet menawarkan teknologi media baru untuk menyajikan olahan informasi. Media cetak yang melakukan ekspansi ke media online mulai berusaha membawa narasinya ke format baru di media tersebut.

Pablo Bockzowski memaparkan bahwa terdapat tiga teknik dalam mengolah informasi yang mulai dicangkokkan oleh media cetak ke dalam format onlinenya (Bockzowski dalam Rooze, 2011). Pertama, mendayagunakan kembali konten cetak mereka ke versi online. Teknik ini sesederhana memindahkan bentuk suatu berita dari format cetak ke format online. Kedua, mengkombinasikan informasi yang ada dalam konten cetak mereka dengan konten lain yang berhubungan dari halaman atau situs lain dan juga sebaliknya melalui fungsi teknis yang terdapat dalam website mereka. Di dalam teknik ini fungsi hiperteks sebagai salah satu fungsi utama internet dalam membuat jaringan yang saling terhubung antara satu konten dengan konten yang lain memegang peranan penting. Ketiga, menciptakan konten baru dengan menggunakan kemampuan-kemampuan khusus yang dimiliki oleh suatu website untuk menarasikan cerita.

Infografis digital adalah salah satu bentuk konten baru yang digunakan untuk menarasikan cerita. Penggunaan teks dan gambar yang interaktif menjadi cara baru dalam menarasikan suatu cerita. Menurut Mi-Sun Kim, salah satu cara agar pembaca bisa memahami secara menyeluruh tentang suatu informasi adalah dengan membuat informasi tersebut menjadi personal bagi pembacanya (Kim, 2010). Personalisasi ini dilakukan dengan cara membuat pembaca terlibat secara aktif untuk "berpartisipasi" dan "mengalami" materi informasi yang disajikan secara interaktif. Masih menurut Kim, cara ini akan membuat pembaca merasakan keterlibatan dan pada satu titik juga terhibur.

Infografis digital dan interaktivitas yang dimilikinya membawa tantangan baru dalam penarasian cerita suatu informasi. Cerita dalam media cetak cenderung dipaparkan secara linear dan berturut. Jurnalis (pencerita) memegang kontrol penuh terhadap apa yang ingin disampaikannya. Pembaca mengikuti alur yang dipaparkan. Sementara, dalam infografis digital pembaca ditempatkan sebagai pengguna yang aktif mengeksplorasi sendiri informasi yang dipaparkan. Pembaca melihat dan berinteraksi dengan materi yang 
disampaikan. Diperlukan teknik yang berbeda dalam penarasian cerita menggunakan infografis digital, karena adanya faktor interaktivitas dan pemahaman terhadap adanya ruang digital.

\section{METODE PENELITIAN}

\section{Memahami Dunia Digital dan Interaktivitasnya}

Scott McCloud (2008) berpendapat bahwa hiperteks dan model spasial adalah dua pilar dari organisasi informasi di dunia digital masa depan. Dari pernyataan McCloud tersebut dapat ditarik pemahaman bahwa hiperteks menuntun informasi untuk bisa saling terhubung satu sama lain, sementara model spasial di dunia digital berhubungan dengan penataan lapisan kedalaman informasi di ruang digital. Dunia digital memiliki keterhubungan dan kedalaman informasi yang bisa ditata berlapis-lapis. Memahami media digital sebagai sebuah ruang yang memiliki kedalaman merupakan hal yang penting karena hal inilah yang membedakannya dengan media tradisional.

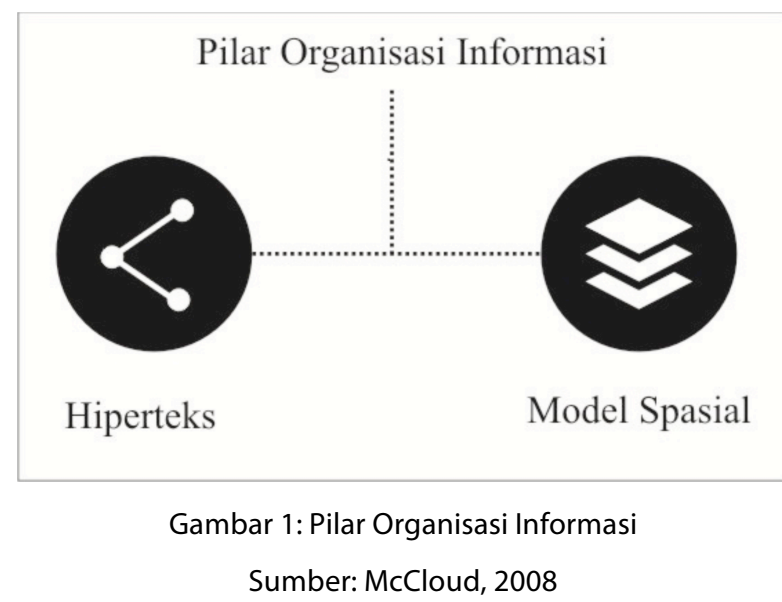

Pemahaman mengenai dunia digital sebagai media yang memiliki keterhubungan dalam suatu kedalaman berlapis penting untuk bisa memahami interaktivitas yang bisa dibangun dari media ini. Donald Norman (2002) dalam bukunya The Design of Everyday Things memaparkan pemahaman dasar tentang interaksi dalam objek desain. la menjelaskan tentang konsep user centered design. Dalam konsep ini, tugas seorang desainer adalah untuk memfasilitasi kebutuhan dari pengguna objek desain dengan lebih mudah. Dalam sebuah desain yang baik, kepentingan pengguna dan interaksi di dalamnya yang memudahkan adalah yang utama. Menurut Norman, jika seorang pengguna mengalami kesulitan dalam penggunaan suatu objek desain, maka yang perlu disalahkan adalah desainer yang tidak bisa mengarahkan dengan baik penggunaan desainnya. Beberapa prinsip Norman bisa diaplikasikan pada perancangan tampilan antarmuka. 
Prinsip utama yang bisa diaplikasikan adalah prinsip keterlihatan (visibility). Desainer bertanggung jawab membuat simbol-simbol yang bermanfaat dan memungkinkan untuk direspon (di-klik) terlihat jelas. Penggunaan warna dan bentuk bisa memberi hierarki visual yang memberi penuntun terhadap kejelasan fungsi elemen tersebut.

Prinsip selanjutnya yang penting adalah prinsip umpan balik (feedback). Dalam prinsip ini, setiap aksi harus selalu diiringi reaksi. Pengguna mendapat pesan atau respon ketika suatu objek bisa digunakan dan bekerja dengan baik. Dalam desain antarmuka yang memiliki interaksi yang baik, umpan balik ini terlihat jelas. Sehingga tidak membuat pengguna frustasi mencari-cari fungsi yang sesuai dengan harapannya.

Prinsip lain yang berhubungan erat dengan prinsip pertama di atas adalah prinsip afordansi. Pada dasarnya dalam desain interaksi, prinsip ini bisa dijelaskan sebagai kualitas yang dimiliki oleh sebuah objek desain yang bisa memberi kejelasan tentang penggunaan dari objek tersebut. Bentuk, warna, posisi dan elemen-elemen yang dimiliki dari suatu objek hendaknya bisa memberi petunjuk bagaimana objek tersebut bisa digunakan atau direspon.

Tabel 1: Prinsip Desain Interaksi dari Norman

\begin{tabular}{|c|c|}
\hline Prinsip & Keterangan \\
\hline $\begin{array}{l}\text { Keterlihatan } \\
\text { (visibility) }\end{array}$ & $\begin{array}{l}\text { Keterlihatan simbol yang memungkinkan untuk direspon } \\
\text { dan berinteraksi dengan pengguna. }\end{array}$ \\
\hline $\begin{array}{l}\text { Umpan balik (feed } \\
\text { back) }\end{array}$ & $\begin{array}{l}\text { Aksi dan reaksi yang memungkinkan pengguna } \\
\text { mendapat pesan atau respon ketika suatu objek bisa } \\
\text { digunakan dan bekerja dengan baik. }\end{array}$ \\
\hline Afordansi & $\begin{array}{l}\text { Kualitas yang dimiliki oleh sebuah objek desain yang bisa } \\
\text { memberi kejelasan tentang penggunaan dari objek } \\
\text { tersebut. }\end{array}$ \\
\hline
\end{tabular}

Sumber: Norman, 2002

\section{Model Narasi Interaktif Dalam Penarasian Cerita Menggunakan Media Digital}

Heer dan Segel (2010) melakukan penelitian terhadap 58 infografis digital (mereka menggunakan istilah "narrative visualization") yang didapat dari berita online (71\%), data bisnis (20\%) dan data penelitian (9\%). Dari data tersebut, mereka memetakan model interaktivitas yang bisa diterapkan dengan mempertimbangkan kebutuhan-kebutuhan pengguna akan informasi maupun kebutuhan informasi itu sendiri untuk dinarasikan oleh 
penutur cerita (desainer infografis digital). Dengan kata lain, terdapat dua sisi dalam pemetaan model interaktivitas tersebut, yaitu author driven dan user driven. Dari hasil penelitian tersebut, mereka menyimpulkan bahwa terdapat tiga jenis model narasi interaktif yang paling umum digunakan dalam suatu infografis digital.

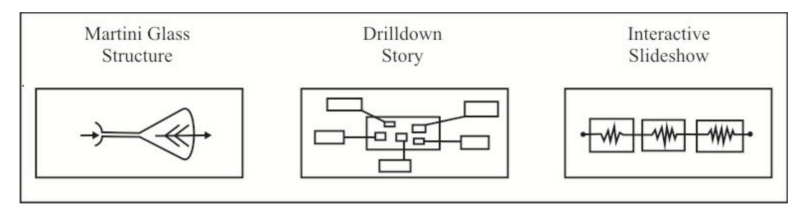

Gambar 2: Model Narasi Interaktif

Sumber: Heer \& Segel, 2010

Pertama, model Martini Glass Structure. Model ini condong memiliki pendekatan narasi author driven. Ciri dari pendekatan ini, awalnya dibuka dari sudut pandang desainer dengan memberi narasi pembuka yang memberi gambaran tentang isi infografisnya. Kemudian, pengguna dibebaskan menjelajah namun tetap terkontrol. Pesan dari desainer ditetapkan di awal untuk menuntun pengguna menjelajahi cerita sesuai tuntunannya. Kebebasan yang ditawarkan tidak akan keluar terlalu jauh dari panduan awal desainer. Infografis digital model ini biasanya hanya menggunakan satu lapisan informasi dengan dilengkapi dengan anotasi-anotasi interaktif yang muncul.

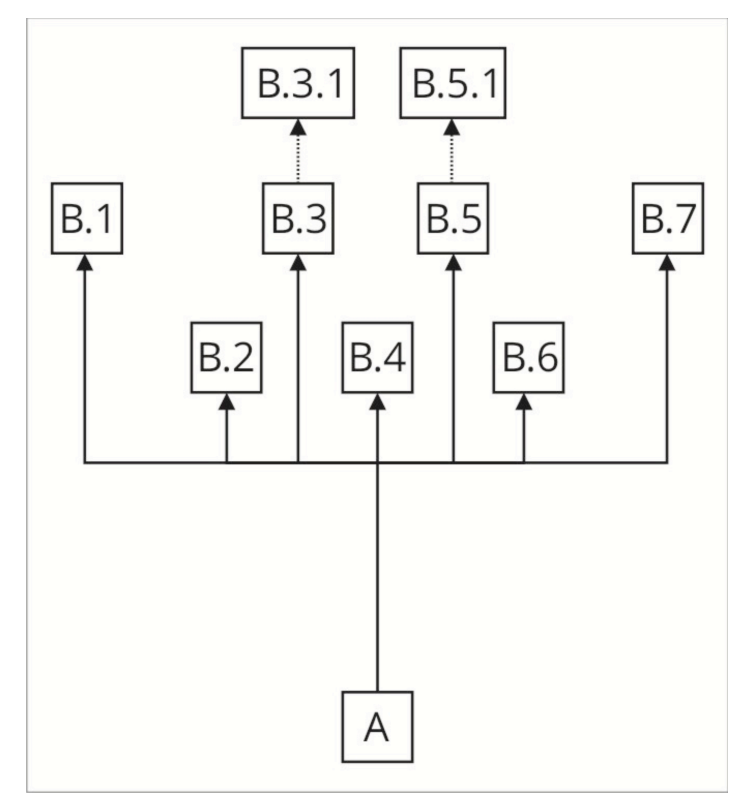

Gambar 3: Martini Glass Structure. Model ini diawali dengan panduan awal (A) untuk kemudian bercabang sesuai pilihan (B1, B2, B3, B4, B5, B6, B7). Untuk memperdalam informasi biasanya hanya digunakan anotasi (B.3.1, B.5.1) Sumber: Penulis, 2014

Kedua, model Drill Down Story. Model ini menempatkan pengguna sebagai pihak yang dominan untuk menggali informasi sesuai keinginannya (user driven). Ciri dari pendekatan 
ini, urutan dan keteraturan gambar bukanlah fokus utama. Tingkat interaktivitasnya tinggi. Ciri dari model ini pengguna bisa memilih sesuka hati jalur yang disediakan oleh desainer. Dari pilihan jalur tersebut, pengguna akan semakin masuk ke dalam informasi yang semakin mendetil. Pengguna mengeksplorasi suatu narasi untuk mengambil kesimpulannya sendiri. Secara garis besar, model ini adalah model yang memberikan kebebasan penuh pada pengguna untuk melakukan ekplorasi suatu infografis dan untuk menemukan kesimpulan-kesimpulannya sendiri.

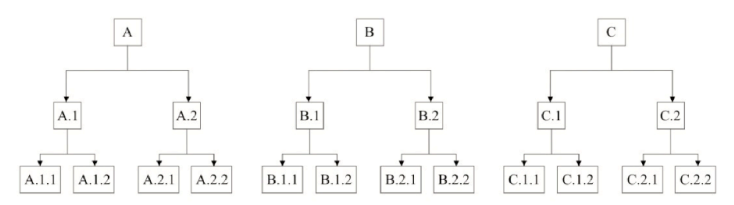

Gambar 4: Drill Down Story. Model ini diawali dengan beberapa pilihan (A, B, C) untuk kemudian bercabang semakin dalam

Sumber: Penulis, 2014

Ketiga, model interactive slideshow. Model ini adalah model yang menggabungkan pendekatan model pertama dengan pendekatan model kedua. Di satu sisi masih terdapat kontrol di dalam narasi ceritanya, di sisi lain juga membebaskan pengguna untuk melakukan eksplorasi informasi sesuai keinginannya sendiri.

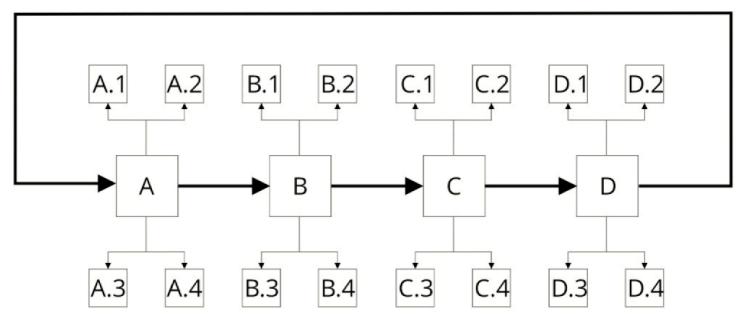

Gambar 5: Interactive Slideshow. Model ini menarasikan ceritanya secara runut (dari A ke B ke C ke D kembali lagi ke A). Namun di tiap lapisan informasinya, pengguna diberi beberapa pilihan informasi yang bercabang sebagai pendalaman Sumber: Penulis, 2014

Heer dan Segel menyampaikan ketiga model tersebut dengan catatan untuk tidak menutup kemungkinan akan adanya kombinasi terhadap ketiga model itu atau munculnya modelmodel lain. 


\section{PEMBAHASAN}

Tempo.co didirikan sejak 1995 dibawah naungan Kelompok Tempo Media (Tempo.co, 2014). Selain menampilkan versi online dari edisi cetak majalah Tempo dan koran Tempo, Tempo.co juga memproduksi konten beritanya sendiri, termasuk menampilkan secara berkala infografis digital dalam situsnya.

Dalam penelitian ini akan dibahas satu infografis digital dari Tempo.co yang menuturkan mengenai kasus korupsi hakim Mahkamah Konstitusi Akil Mochtar sebagai studi kasus mengenai interaktivitas dalam penarasian cerita menggunakan infografis digital. Judul infografis digital tersebut adalah "Akhir Riwayat Sang Hakim". Infografis digital ini dianalisis dengan menggunakan prinsip desain interaksi dari Norman dan model narasi interaktif dari Heer dan Segel. Analisis prinsip desain interaksi ditujukan untuk mengetahui bagaimana desainer infografis digital Tempo.co memahami ruang digital dan membangun interaktivitas di dalamnya. Sedangkan analisis mengenai model narasi interaktif ditujukan untuk mengetahui bagaimana desainer infografis digital Tempo.co memaksimalkan potensi ruang digital untuk membangun narasi ceritanya.

Seperti dikemukakan sebelumnya, memahami dunia digital sebagai media yang memiliki lapisan informasi yang saling terhubung penting untuk bisa memahami interaktivitas yang bisa dibangun dari media ini. Prinsip interaksi di media ini dibangun atas dasar penataan tumpukan lapisan tersebut

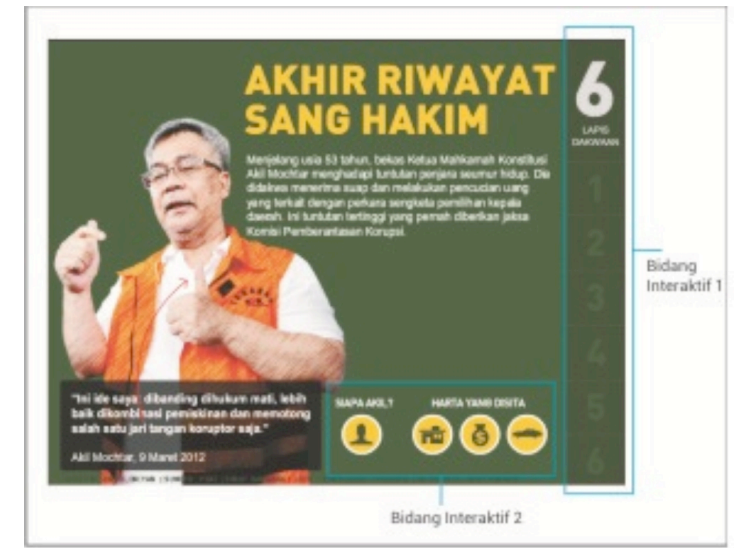

Gambar 6: Halaman Awal dari infografis digital Akhir Riwayat Sang Hakim Sumber: Tempo.co, 2014

Pada infografis di atas terdapat dua grup informasi yang ditata di atas lapisan awal. Dua grup tersebut adalah keterangan mengenai enam lapis dakwaan dan informasi terkait Akil Mochtar. Untuk mengalisis sisi interaktif suatu infografis digital dengan menggunakan prinsip interaksi Norman, terdapat dua tahap yang dilakukan. Tahap pertama adalah analisis 
dari sisi keterlihatan, karena ini adalah tahap awal saat pembaca membuka suatu infografis digital. Tahap kedua adalah analisis mengenai umpan balik pada saat pembaca mulai melakukan interaksi langsung dengan layar lewat mouse dan pointer. Dari dua tahap tersebut bisa dianalisis tingkat afordansi dari suatu desain elemen interaktif.

Pada informasi mengenai enam lapis dakwaan, desainer infografis digital berusaha menampilkan elemen interaktifnya dengan membuat warna abu-abu yang lebih gelap dari sub judulnya (lihat bidang interaktif 1 pada gambar 1). Sedangkan pada informasi terkait Akil Mochtar, desainer infografis menggunakan ikon dan warna kuning terang untuk memberi petunjuk pada pengguna bahwa elemen tersebut bisa direspon (lihat bidang interaktif 2 pada gambar 1). Ketidakkonsistenan kode visual untuk warna yang interaktif ini bisa mengurangi kenyamanan berinteraksi pembaca. Prinsip keterlihatan dalam infografis ini tidak ditunjukkan dengan baik karena kurangnya pemberian petunjuk mengenai adanya lapisan dalam suatu gambar. Teknik yang seringkali dipakai saat ini dalam dunia desain interaksi biasanya dengan menggunakan asosiasi menyerupai bayangan ataupun efek transparansi terhadap latar belakang untuk memberi petunjuk pada pengguna bahwa elemen tersebut berada di atas latar belakang dan bisa direspon selayaknya tombol di realitas dunia nyata. Namun desainer infografis digital ini tidak menggunakan teknik ini ataupun teknik lain untuk menonjolkan fungsi keterlihatan elemen interaktifnya.

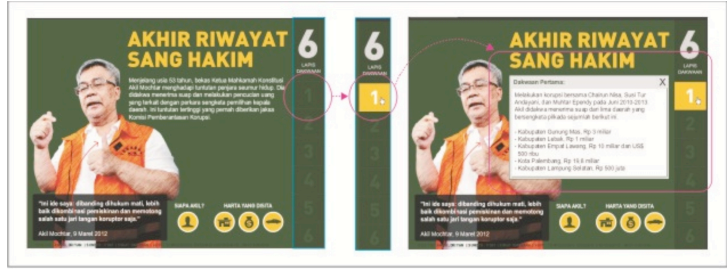

Gambar 7: Prinsip umpan balik bidang interaktif 1 (Sumber: Penulis, 2014)

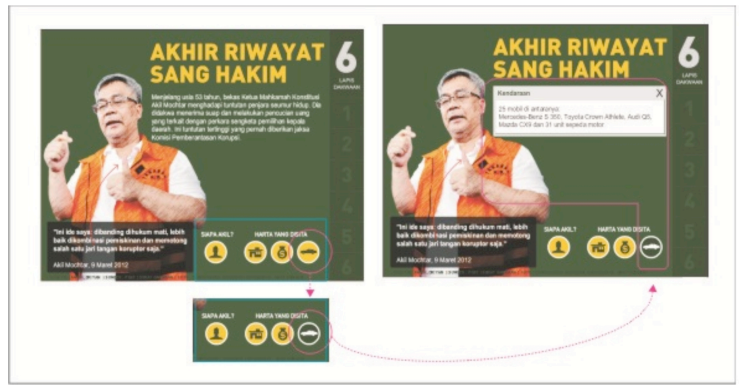

Gambar 8: Prinsip umpan balik bidang interaktif 2 Sumber: Penulis, 2014

Tahap selanjutnya, prinsip umpan balik awal ditunjukkan melalui perubahan-perubahan warna ketika mouse pointer diarahkan pada elemen interaktif. Ketidakkonsistenan warna 
kembali ditunjukkan. Di bidang interaktif 1, strategi umpan balik yang digunakan adalah mengubah warna dari abu-abu ke kuning, sementara di bagian interaktif 2 digunakan perubahan warna sebaliknya. Ketidakkonsistenan kode warna ini bisa menimbulkan pesan yang keliru bagi pembaca, sehingga mengurangi efektivitas penuturan cerita maupun kenyamanan pengguna ketika berinteraksi dengan infografis digital ini. Dari hasil analisis dua prinsip tersebut dapat ditarik analisis selanjutnya mengenai kualitas afordansi elemen interaktif dalam infografis digital ini. Tingkat keterlihatan yang rendah dan ketidakkonsistenan kode warna dalam umpan balik mengurangi kualitas afordansi elemen interaktif dalam infografis digital ini. Suatu elemen interaktif yang didesain dengan tingkat afordansi yang bagus akan memberi kejelasan mengenai penggunaannya. Dalam infografis digital, suatu elemen visual yang dirancang untuk interaktif harus menunjukkan pesan bahwa ia bisa direspon di antara berbagai tulisan dan gambar lainnya. Elemen visual tersebut, perlu memiliki kualitas afordansi yang baik untuk membuka lapisan narasi pendukung dari narasi utama. Sehingga sudah selayaknya elemen interaktif tersebut juga menunjang alur dan tutur cerita.

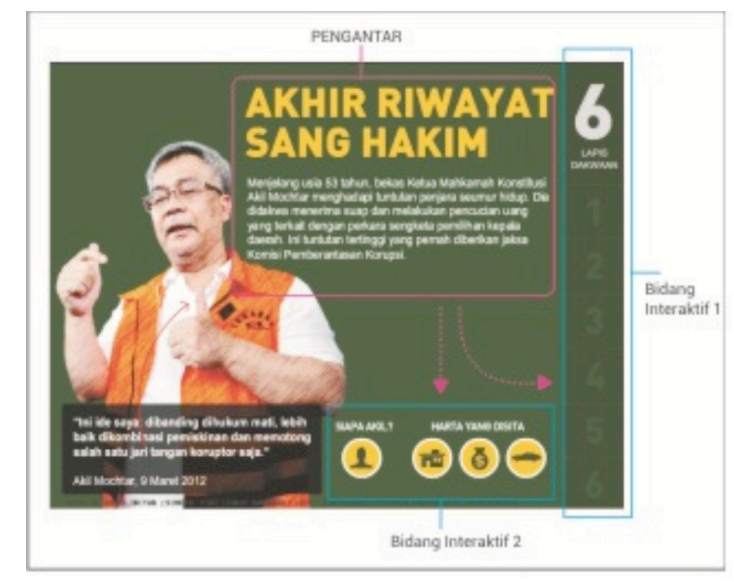

Gambar 9: Model Narasi Interaktif dari infografis digital Akhir Riwayat Sang Hakim (Sumber: Penulis, 2014)

Dari segi alur cerita, model narasi interaktif yang digunakan dalam infografis digital ini adalah model martini glass structure. Desainer membuka dengan headline dan narasi verbal pembuka. Kemudian membebaskan pembaca untuk memilih jalurnya sendiri untuk dieksplorasi. Meskipun cerita yang hendak dituturkan ketat dengan pemilihan hanya satu lapisan informasi dan penggunaan anotasi. Sayangnya desainer tidak memberi pengantar yang cukup baik untuk mengarahkan maupun mengalirkan narasi ceritanya. Dari pembuka ke dua informasi lanjutan yang disembunyikan tidak diberikan petunjuk dengan baik. Desainer infografis seharusnya bisa memberi petunjuk mengenai kesatuan informasi apa saja yang bisa dieksplorasi agar pengguna mendapat pengalaman yang utuh. Informasi 
yang diletakkan tanpa kesatuan akan memberi kesan sekadar ditempelkan pada narasi cerita. Model narasi interaktif yang hanya menggunakan satu lapisan informasi seperti ini memiliki kecenderungan untuk memberi pesan yang terkontrol oleh desainer, namun tantangannya adalah membuat pengguna mau menuruti kontrol narasi yang ditetapkan. Apabila pengantar, narasi keseluruhan dan penataan hierarki lapisan informasi tidak menunjukkan kesatuan, akan memiliki kecenderungan untuk mudah ditinggalkan pembaca.

\section{PENUTUP}

Desain infografis digital mengenai riwayat hakim mahkamah konstitusi ini memiliki tingkat keterlihatan yang rendah dan ketidakkonsistenan kode warna dalam umpan balik elemen interaktifnya sehingga mengurangi kualitas afordansi dari elemen interaktif tersebut. Interaktivitas yang dibangun belum diletakkan dengan baik berdasar pemahaman ruang digital dan prinsip utama desain interaksi. Infografis digital ini juga tidak mampu memaksimalkan potensi yang dimiliki ruang digital untuk mengalirkan narasinya dengan baik. Dengan tidak mengalirkan dengan baik narasinya, infografis digital ini tidak mampu menyampaikan tujuannya dengan jelas, yang bisa berakibat pada ketidaktertarikan dan ketidaknyamanan pengguna dalam berinteraksi lebih lanjut.

Dalam perancangan infografis digital, prinsip keterlihatan elemen interaktif bisa dirancang menggunakan strategi visual yang bermacam-macam, namun yang menjadi dasarnya adalah pemahaman bahwa terdapat lapisan-lapisan dalam suatu ruang digital. Antara latar belakang dan elemen interaktif perlu diberikan petunjuk visual dengan mengadopsi realitas di dunia nyata. Konsistensi sistem visual juga menjadi catatan penting karena ketidak konsistenan penggunaan sistem visual bisa membingungkan dan memberi pesan yang salah pada pengguna. Kombinasi yang tepat antara keterlihatan dan umpan balik dari elemen interaktif akan memberikan afordansi yang baik dan memudahkan pengguna dalam berinteraksi.

Dalam perancangan narasi infografis digital, perlu ditetapkan pesan dan tujuan yang jelas di awal. Pesan tersebut bisa dipaparkan langsung ataupun bisa disembunyikan dengan tujuan agar pengguna mengekplorasi sendiri dan untuk memfokuskan tiap masalah yang ingin diekplorasi. Penyusunan hierarki informasi sangat penting karena berhubungan dengan penerjemahannya ke dalam desain infografis serta penataan lapisan informasi di ruang digital. 
Infografis digital memiliki potensi sebagai cara baru untuk menarasikan informasi. Infografis digital bisa membantu memberi pemahaman dalam penyajian suatu informasi dengan cara yang menghibur. Faktor interaktivitas dari infografis digital tidak hanya untuk menarik perhatian dan membuat pengguna berinteraksi tanpa tujuan. Interaktivitas yang dirancang harus menjadi bagian dari pesan, tidak hanya dekorasi gerak tambahan. Antara fungsi visual, verbal dan interaktivitas harus bekerja secara berdampingan dan memperjelas makna maupun narasi informasi.

\section{DAFTAR PUSTAKA}

Heer, J., \& Segel, E. (2010). Narrative Visualization: Telling Stories with Data. Diambil dari The Stanford

Visualization Group (website:http://vis.stanford.edu/files/2010-Narrative-InfoVis.pdf).

McCloud, Scott. (2008). Mencipta Ulang Komik. Jakarta: Kepustakaan Populer Gramedia.

Norman, D. (2002). The Designs of Everyday Things. New York: Basic Books.

Kim, M. (2010). Paradigm Shift in How People Interact With Media. Diambil dari Parson Journal for Information Mapping (website: http:// pjim.newschool.edu/issues/2012/03/pdfs/ParsonsJournalForInformationMapping_K im_MiSun.pdf).

Rooze, Marije. (2011). Interactivity in the Online Graphics of The New York Times and The Guardian (website: http://mastersofmedia.hum.uva.nl/2011/05/06/interactivity-inonline-graphics-of-the-ny-times-and-the-guardian/ diakses pada tanggal 25 November 2013).

Tempo.co. (2014). About (website Tempo.co http://www.tempo.co/about/ diakses 23 Juni 2014)

Tempo.co. (2014) Akhir Riwayat Sang Hakim (website Tempo.co http:// www.tempo.co/read/flashgrafis/2014/06/23/613/Akhir-Riwayat-Sang-Hakim diakses 23 Juni 2014) 